\title{
Adnexal torsion-five-year retrospective study
}

\section{Latha Maheswari S. ${ }^{1 *}$, Reena Abraham¹, Pavai Arunachalam²}

\begin{abstract}
${ }^{1}$ Department of Obstetrics and Gynecology, ${ }^{2}$ Department of Pediatric Surgery, PSG Institute of Medical Sciences and
\end{abstract} Research, Coimbatore, Tamil Nadu, India

Received: 16 November 2017

Accepted: 18 December 2017

\section{* Correspondence:}

Dr. Latha Maheswari S.,

E-mail: lathamaheshwari@gmail.com

Copyright: (C) the author(s), publisher and licensee Medip Academy. This is an open-access article distributed under the terms of the Creative Commons Attribution Non-Commercial License, which permits unrestricted non-commercial use, distribution, and reproduction in any medium, provided the original work is properly cited.

\begin{abstract}
Background: Adnexal torsion is one of the gynecologic emergency conditions requiring prompt diagnosis and surgical treatment to save the ovarian function. This retrospective study is intended to analyze the clinical manifestations and treatment in a tertiary care center.

Methods: This is a retrospective study Case records during five-year period of February 2012-2017 in PSG Institute of Medical Sciences and research, Coimbatore, India.

Results: Adnexal torsion was seen in all age groups and commonly in reproductive age. It was seen in few pregnant patients also. Lower abdominal pain of acute onset associated with nausea and vomiting was the commonest clinical feature. Ovarian cyst and PCOD were the common risk factors predisposing torsion. Though ultra sound was the common modality used, the diagnosis was done based on strong clinical suspicion with surgical confirmation. The ovaries were preserved in some patients of reproductive age group.

Conclusions: Adnexal torsion is one of the gynecologic emergencies. The symptoms and signs are nonspecific and may not have a confirmatory lab or imaging study. Hence a strong clinical suspicion followed by prompt surgical management in both pregnant and non -pregnant patients of any age group saves the ovary and further complications.
\end{abstract}

Keywords: Abdominal pain, Ovary, Torsion, Ultrasound

\section{INTRODUCTION}

Adnexal torsion is one of the gynecological emergencies affecting females of all ages. Ovarian torsion is defined as rotation of ovary or adnexa with the vascular pedicle on its axis resulting in arterial, venous,or lymphatic obstruction. ${ }^{1}$

It often presents as intermittent acute abdominal pain exacerbated by positional shifts. ${ }^{2}$ Approximately $70 \%$ have symptoms of nausea and vomiting mimicking other surgical causes of pain like acute appendicitis or renal colic. So, the clinical scenario can lead to misdiagnosis. ${ }^{3}$

In addition, the conventional ultrasound may not be conclusive and the diagnosis can become difficult. Delay in diagnosis and treatment leads to necrosis of the affected ovary.

The aim of the study was to analyze the clinical manifestations and management done during the past five years.

\section{METHODS}

A Retrospective analysis of 47 medical records with surgically confirmed cases of adnexal torsion was done. The clinical parameters taken for analyses taken were age, medical history, clinical manifestations and examination findings. In clinical presentation the type of abdominal pain with associated clinical findings were noted. 
Additionally, whether the condition was associated with fever and leukocytosis was also noted. The imaging performed with its findings, operative details and histopathological reports of the specimens were also analyzed.

\section{RESULTS}

\section{Clinical findings}

The total number of patients with ovarian torsion were 47 in number. The median age of our patients was 22 years (18days-66years). There were $5(10.6 \%)$ patients in premenarchal age group, 41 patients $(87.2 \%)$ in reproductive age group and $1(2.1 \%)$ in postmenopausal group. Acute onset of pain was the common symptom present in all patients $(100 \%)$. The abdominal pain was diffuse and nonspecific in 21 patients $(44.6 \%)$, localized to right side in 19 patients $(40.4 \%)$, and on the left side in 7 patients $(14.8 \%)$. The next common symptom was nausea and vomiting seen in $37(78.7 \%)$ patients followed by fever in $5(10.6 \%)$ patients. A mass was palpable in $14(29.7 \%)$ and tenderness elicited in 17 $(36.17 \%)$ of the cases.

There were $3(6.3 \%)$ patients in early pregnancy with torsion.

Lab investigations revealed leukocytosis in $18(38.2 \%)$ and anemia in $4(8.5 \%)$ cases.

In all cases ultrasound along with Doppler was performed and torsion was reported in 25 patients $(53.19 \%) .11$ cases $(23.4 \%)$ had minimal free fluid in pouch of Douglas. Ovarian cyst was reported in 31 cases $(65.9 \%)$ in ultrasound. Of that 16 patients $(51.6 \%)$ had cyst size of 5- $10 \mathrm{cms}, 11$ patients $(35.4 \%)$ had cyst size of more than $10 \mathrm{~cm}$ and 4 patients $(12.1 \%)$ had cyst size of less than $5 \mathrm{cms}$. The contralateral ovary showed features of PCOD in $5(10.6 \%)$ patients.

\section{Operative findings}

Of 47 patients with adnexal torsion, right adnexa was involved in $27(57.4 \%)$ cases followed by $20(42.5 \%)$ cases on left side. The risk factors like tubal ligation was noted in $3(6.3 \%)$ cases, previous surgery adhesions in 1 $(2.1 \%)$ patient.

Isolated fallopian torsion was seen in $3(6.3 \%)$ in patients.

Detorsion with oophoropexy was done in 8 (17\%) patients, ovarian cystectomy was done in $20(42.5 \%)$ patients, unilateral salpingectomy in $3(6.3 \%)$ patients, unilateral salphingo oophorectomy in 11 (23.4\%) cases and total hysterectomy with bilateral salphingo oophorectomy in $5(10.6 \%)$ patients. The patients with conserved ovaries were found to have normal ovarian function and asymptomatic on follow-up.
Table 1: Histopathological examination of the specimens.

\begin{tabular}{|lll|}
\hline HPE findings of specimens & Numbers & $\%$ \\
\hline Serous cyst adenoma & 6 & 12.77 \\
\hline Serous cyst adenofibroma & 1 & 2.13 \\
\hline Serous cyst adeno carcinoma & 1 & 2.13 \\
\hline Mucinous cyst adenoma & 2 & 4.26 \\
\hline Teratoma & 2 & 4.26 \\
\hline Follicular cyst & 1 & 2.13 \\
\hline Corpus luteal cyst & 4 & 8.51 \\
\hline Paraovarian cyst & 5 & 10.63 \\
\hline Endometriotic cyst & 1 & 2.13 \\
\hline Total specimens with & 17 & 36.17 \\
\hline haemorrhagic necrosis & & \\
\hline
\end{tabular}

Histopathological examination was done in all excised specimens and results are shown in Table 1. The common finding seen in specimens was hemorrhagic necrosis (36.1\%) and the common benign tumor noted was serous cyst adenoma in 6 patients $(12.7 \%)$.

\section{DISCUSSION}

Adnexal torsion is the reported to be the fifth most common gynecological emergency condition encountered with a prevalence of $2.7 \% .^{4}$ Though it is fifth most common emergency it poses difficulty to diagnose clinically due to nonspecific presentation. The lower quadrant abdominal pain described in adnexal torsion is of sudden onset usually following exercise or jerky movement. It is described as sharp, stabbing or less frequently crampy. ${ }^{5}$ The ultrasound findings of ovarian torsion may change depending on the duration and degree of torsion (Complete or incomplete) and the presence or absence of ovarian mass. ${ }^{6,7}$ The other adnexal pathologies like endometriosis, hemorrhagic cysts, ectopic pregnancy, pelvic inflammatory disease form complex adnexal mass and make it difficult to differentiate sonographically. ${ }^{4,8,9}$

All age groups are susceptible to develop adnexal torsion though it is commonly seen in reproductive women. . $^{3,10-12}$ Majority of our cases in this study also were in younger reproductive age group (Table 2). It commonly occurs in normal ovaries in young children. ${ }^{13}$ Torsion was seen in 5 $(10.6 \%)$ of our cases in premenarchal age group. Our youngest patient was 18 days neonate, prenatally diagnosed to have an ovarian cyst. Oltmann SC et al reports occurrence of $16 \%$ in infant population. ${ }^{14}$ It was less common in post-menopausal women in this study.

The most common symptom seen in all our cases (100\%) was acute onset of abdominal pain. Other studies also reported the increased incidence of acute abdominal pain. ${ }^{12,15}$ In respect to site of pain $21(44.6 \%)$ cases had diffuse pelvic pain, $19(40.4 \%)$ cases had pain on right flank and $7(14.8 \%)$ cases on the left flank. The site of pain may not always denote the site of torsion because twisted adnexal masses are often midline, positioned cranial to the uterine fundus of abdominal pain. ${ }^{1}$ The next 
common symptom in this study was nausea and vomiting seen in $37(78.7 \%)$ cases similar to other studies. ${ }^{11,14}$ In this study palpable mass was seen in $14(29.7 \%)$ cases and tenderness was demonstrated only in $17(36.1 \%)$ cases and was similar to another study. ${ }^{12}$ Other symptoms like vaginal bleeding and urinary symptoms reported in other studies were not noted in this study. ${ }^{11,16}$

Table 2: Present study compared with other studies.

\begin{tabular}{|c|c|c|c|}
\hline Details & Our study & Shoba Nair et al & C Spinelli et al \\
\hline Number of patients & 47 & 70 & 30 \\
\hline Age & 18 days-66y & $11 y-91 y$ & 2 months-18 y \\
\hline Premenarchal age & $10.60 \%$ & $2.90 \%$ & \\
\hline Reproductive age $<45$ yrs & $87.20 \%$ & $82.60 \%$ & \\
\hline Parity & $31.90 \%$ & $50.00 \%$ & \\
\hline Pregnancy & $6.30 \%$ & $2.90 \%$ & \\
\hline Menopause & $2.10 \%$ & $17.00 \%$ & \\
\hline Pain abdomen & $100.00 \%$ & $95.70 \%$ & $100.00 \%$ \\
\hline Nausea/Vomiting & $78.70 \%$ & $65.70 \%$ & $56.70 \%$ \\
\hline Fever & $10.60 \%$ & $12.90 \%$ & $20.00 \%$ \\
\hline leukocytosis & $38.20 \%$ & $44.00 \%$ & $63.30 \%$ \\
\hline Palpable mass & $29.70 \%$ & $42.90 \%$ & \\
\hline Tenderness & $17.00 \%$ & $25.70 \%$ & \\
\hline USG diagnosed torsion & $53.19 \%$ & $25.70 \%$ & $63.00 \%$ \\
\hline USG Free fluid POD & $23.40 \%$ & $23.80 \%$ & $26.70 \%$ \\
\hline Right side & $57.40 \%$ & $55.70 \%$ & $70.00 \%$ \\
\hline Left side & $42.50 \%$ & $42.90 \%$ & $30.00 \%$ \\
\hline Size $5-10 \mathrm{~cm}$ & $51.60 \%$ & $71.40 \%$ & \\
\hline Size $>10 \mathrm{~cm}$ & $35.40 \%$ & $11.40 \%$ & \\
\hline Serouscystadenoma & $12.70 \%$ & $15.70 \%$ & \\
\hline Mucinouscystadenoma & $4.20 \%$ & $7.10 \%$ & $3.30 \%$ \\
\hline Teratoma & $4.20 \%$ & $22.80 \%$ & $16.70 \%$ \\
\hline Hemorrhagic necrosis & $36.10 \%$ & $30.40 \%$ & \\
\hline Conservative surgery & $59.50 \%$ & $54.30 \%$ & $46.70 \%$ \\
\hline Radical surgery & $40.30 \%$ & $45.70 \%$ & $53.30 \%$ \\
\hline
\end{tabular}

Adnexal torsion can occur rarely in pregnancy. The incidence reported is 1 in 5000 and occurs more frequently in the first trimester in patients that underwent treatment for infertility with in vitro fertilization or ovarian stimulation. ${ }^{17}$ Present study had 2 cases of adnexal torsion in first trimester and one case in second trimester of pregnancy. Similar case series also reports torsion common in first trimester and less common in second and third trimesters. ${ }^{18}$ The diagnosis of torsion in pregnancy becomes more challenging and also there is tendency to go for conservative approach. Adnexal torsion requires surgical intervention in pregnancy with preservation of corpus luteum. Organ preservation is important for the continuity of the pregnancy and a study by Oelsener et al reports performing detorsion in all 40 cases of torsion regardless of the macroscopic appearance. $^{19}$

Fever and leukocytosis was seen in $5(10.6 \%)$ and 18 $(38.2 \%)$ cases respectively. Nurith et al reports incidence of fever in $20 \%$ and leukocytosis in $43 \%$ of cases. ${ }^{15}$ Fever and leukocytosis occurs due to adnexal mass necrosis. Four patients had anemia, and of that one had $6 \mathrm{gm} \%, 2$ cases had $7 \mathrm{gm} \%$ and one had $8 \mathrm{gm} \%$ which is similar to another study. ${ }^{11}$ Anemia is usually rare in cases with ovarian torsion and may be seen in few patients due to occurrence of hemorrhagic necrosis.

Ultrasound as a modality to diagnose torsion is found to have a senstivity of $63 \%-95 \%$ due to difficulty in interpretation. ${ }^{1,14,20}$ Normal adnexal appearance is common in $69 \%$ of premenarchal patients. ${ }^{21}$ Some studies $^{9,20}$ show enlarged ovary with multiple peripheral follicles as sign of torsion with a sensitivity of $64-74 \%$. So, to improve the detection rate further studies have focused on blood flow using doppler. ${ }^{22}$ Since there is possibility of arterial flow in cases of partial type or early adnexal torsion it led to further studies to improve detection rate to $88-95 \%$ by focusing on twisted pedicle described commonly as whirlpool sign. ${ }^{1,23}$ In present study torsion was diagnosed using ultrasound with doppler in $53.19 \%$ of our cases. The ultrasound finding showing presence of ovarian cyst in 31 (65.9\%) cases suggests that it is the common risk factor in most of our 
cases, especially if the size was $5-10 \mathrm{~cm}$ in $16(51.6 \%)$ followed by size $>10 \mathrm{cms}$ in 11 cases $(35.4 \%)$ and size of $<5 \mathrm{~cm}$ in $4(12.9 \%)$ cases. Ovarian cyst as common risk factor was reported by Oltmann SC et al. ${ }^{24}$ It was noticed polycystic ovary in $5(10.6 \%)$ cases as the next common risk factor. In young women polycystic ovary is reported to be a common risk factor for adnexal torsion. ${ }^{11}$

Regarding the side of torsion our study showed right side was involved in $27(57.4 \%)$ cases and on left side in 20 $(42.5 \%)$ cases. Other studies also similar findings. This could be because of long right ovarian ligament or presence of sigmoid on the left side. ${ }^{12,14}$ Isolated tube torsion was seen in three $(6.3 \%)$ cases. No specific risk factors like hydrosalpinx was seen in our cases.

Previously oophorectomy or salphingo oophorectomy was the preferred procedure fearing the possibility of gangrenous transformation and sepsis. Now recently the studies show preserved ovaries maintains its function on follow up. ${ }^{25}$ In present study $8(17 \%)$ cases had undergone detorsion and oopheropexy, 20 (42.5\%) had ovarian cystectomy, 3 cases $(6.3 \%)$ had unilateral salphingectomy, 5 cases $(10.6 \%)$ had hysterectomy with bilateralsalphingo oophorectomy, and 11(23.4\%) cases underwent unilateral salphingo oophorectomy. In total, conservative surgery was done in $59.5 \%$ of patients and radical surgery in $40.3 \%$ of patients (Table 2). Removal of adnexa was performed in patients having a gangrenous mass and ovarian preservation was done in cases having edematous or bluish black ovaries. On follow up patients with preserved ovaries were comfortable, was asymptomatic and showed evidence of ovarian function.

Histopathology examination (Table 1) showed benign conditions in most specimens and were associated with hemorrhagic necrosis commonly. The common benign tumor was serous cyst adenoma followed by mucinous cyst adenoma and teratoma. One of patients diagnosed as malignancy had torsion following the completion of third cycle of presurgical chemotherapy. But the pain was misdiagnosed as ureteric colic and was treated conservatively before taking up for surgery. There are other case series reporting the rarity of malignant tumour undergoing torsion. ${ }^{24}$

\section{CONCLUSION}

Diagnosis of adnexal torsion is a challenge to both clinician and radiologist due to its nonspecific clinical and radiological findings. So, it requires strong clinical suspicion and radiological expertise. Early diagnosis and surgical management saves the ovary, thereby preserving its function.

\section{Funding: No funding sources} Conflict of interest: None declared

Ethical approval: The study was approved by the Institutional Ethics Committee

\section{REFERENCES}

1. Vijayaraghavan SB. Sonographic whirlpool sign in ovarian torsion. J Ultrasound Medic. 2004;23(12):1643-9.

2. Mc Williams GD, Hill MJ, Dietrich CS. Gynaecologic emergencies. Surg Clin North Am. 2008;88:265.

3. Niafar F, Mirfendereski S, Rostamzadeh A. Diagnostic efficacy of sonography for diagnosis of ovarian torsion. Zahedan J Res Med Sci. 2014;16(11):37-9.

4. Hibbard LT. Adenxal torsion. Am J Obstet Gynecol. 1985;152:456-61.

5. Schraga ED. Ovarian torsion: Practice Essentials. Available

https://emedicine.medscape.com/article/2026938overview

6. Rosado WM Jr, Trambert MA, Gosink BB, Pretorius DH. Adnexal torsion;diagnosis using Doppler sonography. AJR Am J Roentgenol. 1992;159:12513.

7. Fleischer AC, Stein SM, Cullianan JA, Warner MA. Colour Doppler sonography of adnexal torsion. J Ultrasound Med. 1995;14;523-8.

8. Warner MA, Fleischer AC, Edell SL, Thieme GA, Bundy AL, Kurtz AB, et al. Uterine adnexal torsion: sonographic findings. Radiology 1985;154:773-5.

9. Graif M, ItzchacY. Sonographic evaluation of ovarian torsion in childhood and adolescence. AJR AmJ Roentgenol. 1988;150:647-9.

10. Tsafrir Z, Hasson J, Levin I, Solomon E, Lessing JB et al. Adnexal torsion: cystectomy and ovarian fixation are equally important in preventing recurrence. Eur J Obstet Gynecol Reprod Biol. 2012;162:203.

11. Nair S, Joy S, Nayar J. Five year retrospective case series of adnexal torsion. JCDR. 2014 Dec;8(12):OC09.

12. Vijayalakshmi K, Reddy GM, Subbiah VN, Sathiya S, Arjun B. Clinico-pathological profile of adnexal torsion cases: a retrospective analysis from a tertiary care teaching hospital. JCDR. 2014 Jun;8(6):OC04.

13. Karman E, Beger B, Cetin O, Melek M, Karaman Y. Ovarian Torsion in the normal ovary. A Diagnostic Challenge in adolescent girls in Emergency Department. Med Sci Monit. 2017;23:1312-6.

14. Spinelli C, Buti I, Pucci V, Liserre J, Alberti E, Nencini $\mathrm{L}$ et al. Adnexal torsion in children and adolescents: new trends to conservative surgical approach-our experience and review of literature. Gynaecol Endocrinol. 2013:29(1):54-8.

15. Hiller N, Appelbaum L, Simanovsky N, Lev-Sagi A, Aharoni D, Sella T. CT features of adnexal torsion. Am J Roentgenol. 2007 Jul;189(1):124-9.

16. Lo LM, Chang SD, Horng SG, Yang TY, Lee CL, Liang CC. Laparoscopy versus laparotomy surgical intervention of ovarian torsion. J Obstet Gynaecol Res. 2008;34(6)1020-5. 
17. Mancusco A, Broccio G, Angio LG, Pirri V. Adnexal torsion in pregnancy. Acta Obstet Gynecol Scand. 1997;76(1);83-4.

18. Ventolini G, Hunter L, Drollinger D, Hurd WW. Ovarian Torsion during pregnancy. Resident Staff Physician. 2007;12(1):1-4.

19. Oelsner G, Shashar D. Adnexal torsion. Clin Obstet Gynecol. 2006;49(3):459-63.

20. Graif M, Shalev J, Strauss S, Engelberg S, Mashiach S, Itzchak Y. Torsion of the ovary: sonographic features. Am J Roentgenol. 1984;143(6):1331-4.

21. Ganer Herman H, Shalev A, Ginat S, Kerner R, Keidar R, Bar J et al. Clinical characteristics of adnexal torsion in premenarchal patients. Arch Gynecol Obstet. 2016 Mar 1;293(3):603-8.

22. Fleischer AC, Brader KR. Sonographic depiction of ovarian vascularity and flow. Current improvements and future applications. J Ultrsound Med. 2001;20(3):241-50.
23. Lee EJ, Kwon HC, Joo HJ, Suh JH, Fleischer AC. Diagnosis of ovarian torsion with color Doppler sonography; depiction of twisted vascular pedicle. J Ultrasound Med .1998;17(2):83-9.

24. Oltmann SC, Fischer A, Barber R, Huang R, Hicks B, Garcia N. Cannot exclude torsion: a 15year review. Pediatric Surg. 2009;44:1212-6.

25. Lasso BC, Garrido PJ, Murcia PF, Granero CR, Vargas CV, Paredes ER. Ovarian torsion long term follow up of the black- bluish ovary after laparoscopic detorsion. Cir Pediatr. 2014;27(1):2630.

Cite this article as: Maheswari LS, Abraham R, Arunachalam P. Adnexal torsion-five-year retrospective study. Int J Reprod Contracept Obstet Gynecol 2018;7:508-12. 